\title{
Risk Mitigation through Tolerance Strategies for Design in Modularization
}

\author{
Yasaman SHAHTAHERI ${ }^{1}$, Christopher RAUSCH ${ }^{2}$, \\ Jeffrey WEST $^{2 *}$, Carl HAAS ${ }^{2}$, Mohammad NAHANGI ${ }^{2}$ \\ ${ }^{1}$ Department of Civil and Environmental Engineering, \\ Virginia Polytechnic Institute and State University, Blacksburg, Virginia, USA, 24061 \\ ${ }^{2}$ Department of Civil and Environmental Engineering, \\ University of Waterloo, Waterloo, Ontario, Canada, N2L 3G1 \\ *Corresponding author's e-mail: jswest@uwaterloo.ca
}

\begin{abstract}
Current approaches for solving tolerance-related issues in modular construction consist of trial and error tactics, which are inefficient, time-consuming and not risk-averse. Although tolerance management is not new to the construction industry, tolerance issues are usually more problematic for module interfacing and transportation in modular construction. This paper introduces a framework for the development of tolerance strategies for mitigating risks in modular construction systems. Risks affecting specific types of modular projects were investigated and developed into a comprehensive tolerance strategy, which was then validated through a case study of an industrial pipe chassis. The proposed methodology may be more effective than the conventional approach for tolerance definition (i.e., trial and error methods), and has the potential to eliminate rework, decrease project costs and reduce delays experienced in modularization by providing a range of pareto-optimal design solutions for "strict" to "loose" tolerance control with respect to the hypothesized costs and risks.
\end{abstract}

\section{KEYWORDS}

Tolerance; Modular Construction; Modularization; Risk Management; Design Strategies; Decision Framework

\section{INTRODUCTION}

Traditional "stick-built" methods of construction are based on the premise of having skilled crafts and trades working together on a site to complete a construction project. Many sectors of construction are shifting away from this traditional paradigm and towards the use of prefabrication and modularization due to advantages which include shorter project schedules, lower costs, increased safety and improved quality control (Burke and Miller 1998; Nadim and Goulding 2010; Yu et al., 2013). Despite the advantages of modular construction, several constraints or challenges exist with respect to project pre-planning, project coordination, preliminary design and transportation (Haas et al., 2000; Goodier and Gibb 2005; O'Connor et al., 2014). These constraints often lead to the formation of risks, which can have a profound impact on the benefits of modularization. This is evident through limited initial design options, complex interfacing, long lead-in times, delayed planning processes, and design inflexibility (Haas et al., 2000; Pan et al., 2007; Taylor et al., 2009).

Modularization also presents risks related to module damage and interfacing problems resulting in rework and project delays (Taylor et al. 2009). The reduction of these tolerance-related risks in modularization is normally approached by specifying strict fabrication tolerances. However, 
tolerance problems often still persist for two reasons: (1) discontinuity between tight fabrication tolerances and highly variable site-interface tolerances, and (2) module distortions and damage occurring during transportation and handling which are not anticipated during the initial design. Despite utilizing strict fabrication tolerances, erection is still often problematic requiring rework and delays. The research described herein introduces a framework for using risk-based tolerance strategies to address and mitigate some of the tolerance-related problems associated with modularization.

\section{BACKGROUND}

Modularization provides a manufacturing approach to conventional construction practices in architectural, engineering, and construction (AEC) projects. As such, it is valuable to understand the previous research and standard operation procedures for tolerance strategies in manufacturing. Modularization takes advantage of the economies of scale seen in the mass production of manufacturing, but also requires traditional "stick-built" practices regarding construction of foundations, service tie-ins, and module erection (Gann 1996; Gibb 2001). Therefore, tolerance strategies for modularization should combine certain concepts and underlying premises of tolerance strategies used in both manufacturing and AEC industries. Due to production repetition, the need for interchangeable parts and technological advancements, tolerance analysis and specification is well-researched and widely used within the manufacturing industry (Gadzala, 1959; Hong and Chang 2002; Sutherland and Roth 1975). Tolerance specification is often regarded as the critical link between engineering design and production, since engineers rely on component precision (strict tolerances) for intended form and function, while manufacturers rely on flexibility (loose tolerances) for ease of fabrication and assembly (Chase and Greenwood 1988). Having a methodology for tolerance strategies is an effective way to merge the opposing aims of functionality and manufacturability. While tolerance strategies are common within the manufacturing industry, the use of tolerance strategies is not as widespread in the AEC industry, since practitioners do not often attribute problems in construction to inadequate specification and control of tolerances (Milberg and Tommelein 2005).

Previous researchers have developed computerized tools and score-based outlines which support the decision making process for the optimal use of prefabrication, preassembly, modularization and offsite fabrication (PPMOF) in industrial projects (Song et al., 2005). 3D automated design tools have been used for design configuration and assembly planning to ensure constructability, proper sequencing and identification of potential dimensional conflicts between components and systems (Neelamkavil 2009). With respect to fabrication, the use of precision fixturing (e.g., framing tables), robotic automation, BIM and 3D sensing can help facilitate precise fabrication practices which aid in the implementation of design specifications and erection (Bosche and Haas 2008; Lu and Korman 2010; Nahangi et al., 2015). While these tools are valuable, they only provide a "snapshot" of expected results based on current PPMOF practices and do not provide designers with a means of making risk-based decisions to avoid rework during transportation and erection. Therefore, there is a need for the development of a decision framework to give designers a risk-based approach to defining tolerances in modularization.

\section{PROPOSED METHODOLOGY}

The proposed risk management process is comprised of three stages: (1) risk identification and analysis, (2) development of a tolerance strategy, and (3) the control and monitoring of design strategies. Tolerance strategies outline the relationships between fabrication and site tolerances in

order to optimize the trade-offs between the costs for engineering, materials, fabrication and 
transportation and the risks (or costs) associated with field-fitting and rework. By studying these trade-offs (Figure 1), tolerances can be specified in a manner which minimizes the risk for negative events to occur. As such, tolerance specification is one particular part of the design process which has a direct impact on the amount of rework encountered in modular construction projects.

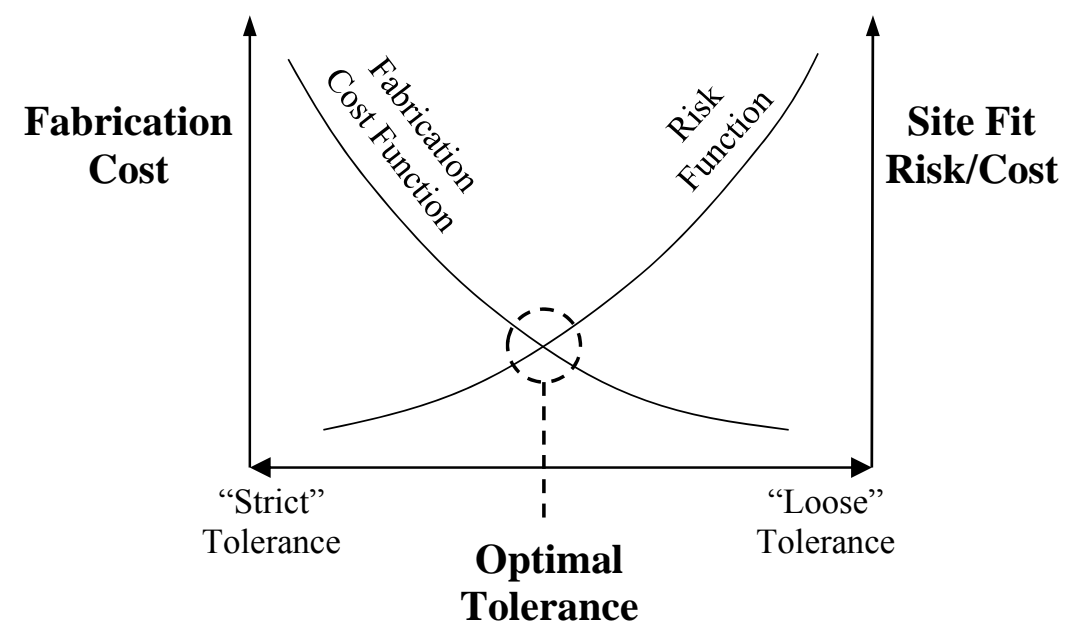

Figure 1. Selecting tolerances to balance trade-offs between module fabrication and site fit cost

The practitioner making preliminary design decisions in modularization should identify what types of tolerances need to be monitored and controlled throughout the project stages. For this purpose, the potential sources of tolerance non-compliance need to be identified, and then the practitioner can develop a comprehensive strategy in order to meet tolerance objectives. For each tolerance strategy, the modular designer must determine how many design option iterations to undertake (increasing the number of iterations will produce a more in-depth analysis, but consequently becomes more time consuming, meaning that there is a balance between time invested and the quality of tolerance strategy), and must also ensure that each design iteration fulfills required design criteria (Figure 2). Analysis of design options involves developing a total cost function and an associated tolerance value for each design which captures the net costs associated with fabricating the module (inclusive of materials and labour) and any corrective rework resulting from negative events caused by risk generation during fabrication, transportation, handling and on-site erection. The second part of the analysis of design options is determining tolerance criteria associated with a particular design option (Figure 3). The modular designer must choose which tolerance metric they are evaluating in their strategy. Depending on what design choice is being made, the tolerance metric can either be explicitly or implicitly related to the tolerance objectives (geometry and goodness of interface-fitting).

\section{CASE STUDY: MODULAR INDUSTRIAL PIPE CHASSIS}

A case study was investigated to demonstrate how tolerance strategies can be used in design to yield an optimal solution which balances fabrication cost and various risks. The case study explored the structural configuration of an industrial pipe chassis (Figure 4.a) that was fabricated for a large assembly in an industrial energy-sector project. Detailed geometric and structural properties of this module were made available by an industry partner (Shahtaheri, 2014). 


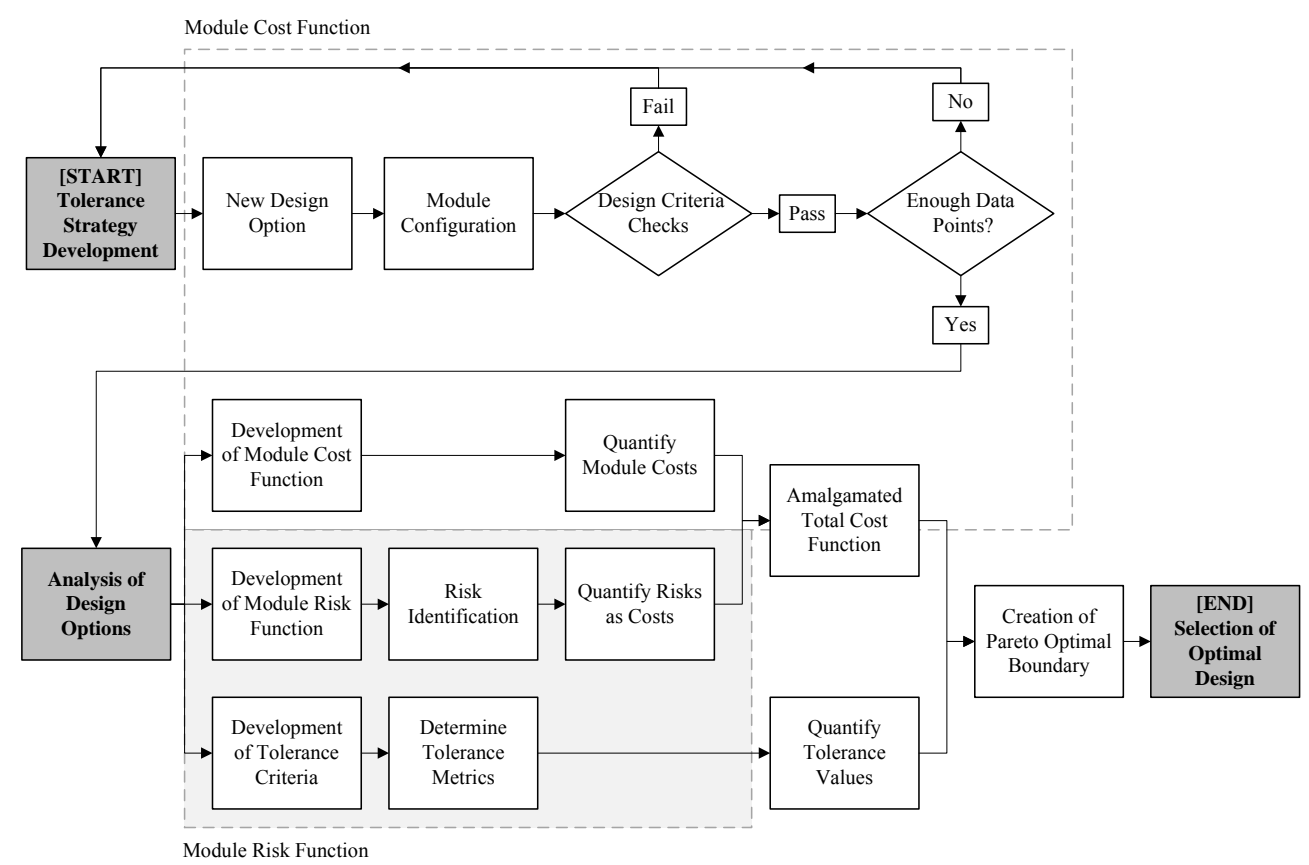

Figure 2. Process for development of tolerance strategies in modularization

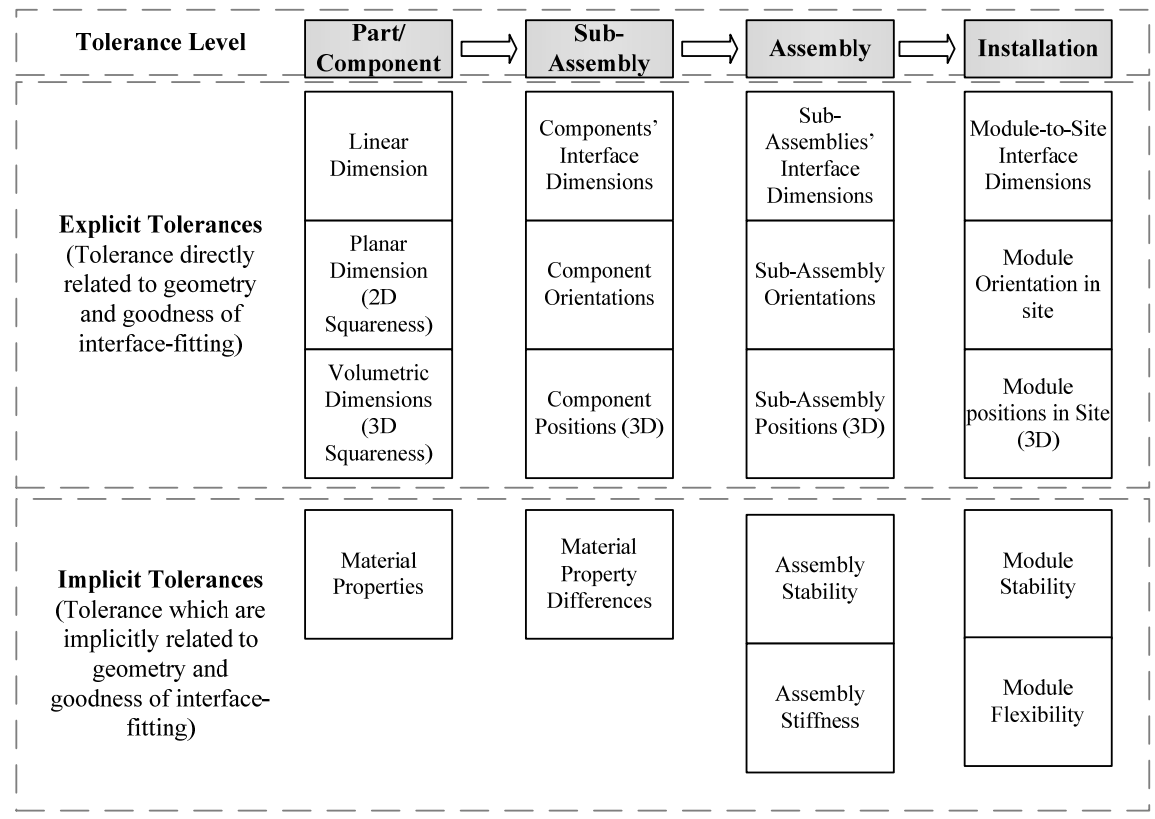

Figure 3. Breakdown of tolerance metrics within modularization

The tolerance strategy involved development and analysis of 61 different structural design options, which varied in nature from various cross-sections (shape and size), to alternative configurations (location and orientation of structural members), to the use of different connection types (i.e., fixed, pinned, or pin-fuse joints). The development process for the tolerance strategy was based on the steps of: (1) Determining module configurations, (2) Performing required design checks, (3) Deriving an amalgamated total cost function, and (4) Creating a Pareto Optimal Boundary. The as-built module was used for the first configuration, and changes to this 
model were used for subsequent configurations. Structural analyses were based on specified loading which included transportation, handling and erection loads (inclined gravity loads, acceleration/deceleration loads, and vertical acceleration loads), as well as "in-situ" loads (selfweight and pipe service loads, since this module supports various piping). Each design included strength and stability checks using a structural analysis program (SAP2000), and adhered to building codes and industry standard requirements (Shahtaheri, 2014). The amalgamated total cost function was comprised of a fabrication cost including labour, equipment and materials, and a cost for total risk. Construction cost data were obtained using published information (Waier et al., 2009) for the purposes of the case study. Each cost function was derived with respect to a specific tolerance value. The tolerance metric chosen in this case study was the assembly distortion, and for ease of analysis was expressed in terms of a critical storey-drift value (lateral deflection divided by the vertical height) resulting from the applied transportation, handling, erection and service loads (Figure 4.b).

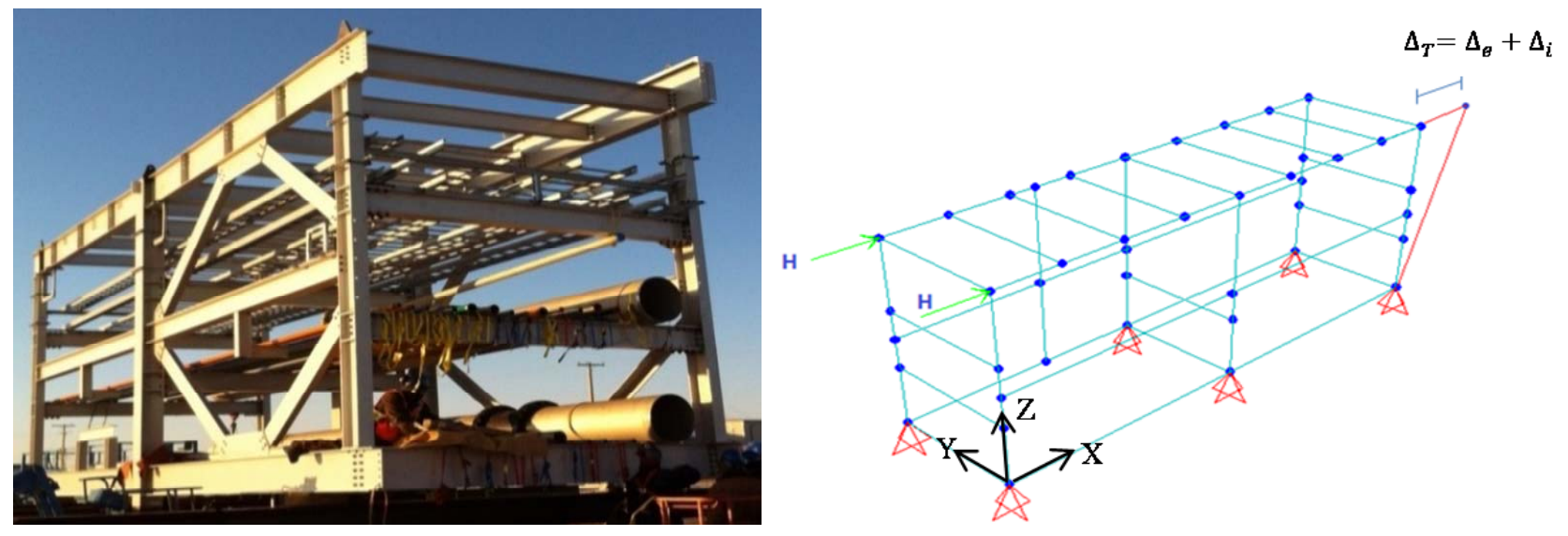

Figure 4. Pipe chassis module examined in case study 1: (a) photograph and (b) graphical demonstration of tolerance metric, storey drift $\left(\Delta_{\mathrm{T}}\right.$ is the resultant storey drift, comprised of an elastic distortion, $\Delta_{\mathrm{e}}$ and an inelastic distortion, $\Delta_{\mathrm{i}}$ )

Although the stiffness of each assembly was measured with respect to a critical storey-drift, the effects of recoverable elastic distortions (not affecting alignment risk) and non-recoverable plastic distortions (affecting alignment risk) were modelled using three different connections in the structural analyses: linear-elastic, elastic-plastic and stiffening hinges. With these hinge types, analyses were performed to determine the amount of permanent distortion to the module requiring rework during erection (Shahtaheri, 2014).

The risk function for each structural configuration consisted of four separate aspects based on the major risks identified prior to development of the tolerance strategy: fabrication rework, transportation, alignment, and safety (Shahtaheri, 2014). The fabrication rework risk considered costs to fix fabrications errors, misalignments, and out-of-tolerances occurring after fabrication but before transportation. This function consists of a one day rework event, which has an increasing rework probability when moving from a heavily-reinforced to a lightly-reinforced module. The transportation risk considered transportation costs, shipping insurance claims, and rework to remedy dimensional degradation from inadequate module stiffness during transportation loads. This function also has an increasing rework probability when moving from a heavily-reinforced to a lightly-reinforced module. It should be noted that the rework event for the 
transportation cost function is a function of the total fabrication cost due to the fact that deformations caused during transportation could be more severe than other sources of out-oftolerance, and may require partial or complete module replacement. The alignment risk considered costs to align the module (including costs to distort or bend the module if needed for proper site-fitting) and any rework to repair damage during fabrication, transportation, and handling. This function includes on-site erection costs and has an increasing rework probability when moving from a heavily-reinforced to a lightly-reinforced module. The safety risk considered the probability of work-place injuries arising during additional labor time associated with rework and was calculated using an hourly Workers Compensation (WC) Insurance cost. All risk associated with rework was quantified by multiplying a probability of rework by an assumed rework event cost (Table 1).

Table 1. Risk function details

\begin{tabular}{|c|c|c|c|}
\hline Risk Functions & $=$ & Multipliers & Rework Event \\
\hline Rework & & probability: $(0.01$ to 0.8$)$ & 5 crews of workers $\times 8 \mathrm{hr} /$ day $\times 125(\$ \mathrm{hr})$ \\
\hline Transportation & & $\begin{array}{l}\text { sional degradation probability: } \\
0.8)+ \text { Insurance rate] }\end{array}$ & Total fabrication cost \\
\hline Alignment & & $\begin{array}{l}\text { actor }{ }_{1}+\text { Scale factor } \text { fa }_{2} \times \\
\text { drift }]=(0.85+100 \times \text { Storey drift })\end{array}$ & $\begin{array}{l}25 \% \times \text { Total onsite erection labour hours } \times \\
125(\$ \mathrm{hr})\end{array}$ \\
\hline Safety & & s Compensation (WC) & $\begin{array}{l}\text { Total labour hours } \times 125(\$ \mathrm{hr})+\text { Rework } \\
\text { risk function }\end{array}$ \\
\hline
\end{tabular}

This case study analyzed 61 structural configurations and generated a data set comparing total cost (including fabrication and total risk costs) to corresponding tolerance values (expected storey drift or distortion). From this plot, a Pareto Optimal Boundary was created, representing the minimum amount of construction cost/risk associated with the smallest allowable distortion or deformation. The right side of this boundary represents designs which have large, or "loose" tolerance values (large permissible storey-drift), and the left side of the boundary represents options which have low, or "strict" tolerance values (small permissible storey-drift). The design configuration with the lowest expected cost is on the bottom of the curve, which is the optimal configuration in terms of balancing costs for fabrication and associated total risk (Figure 5).

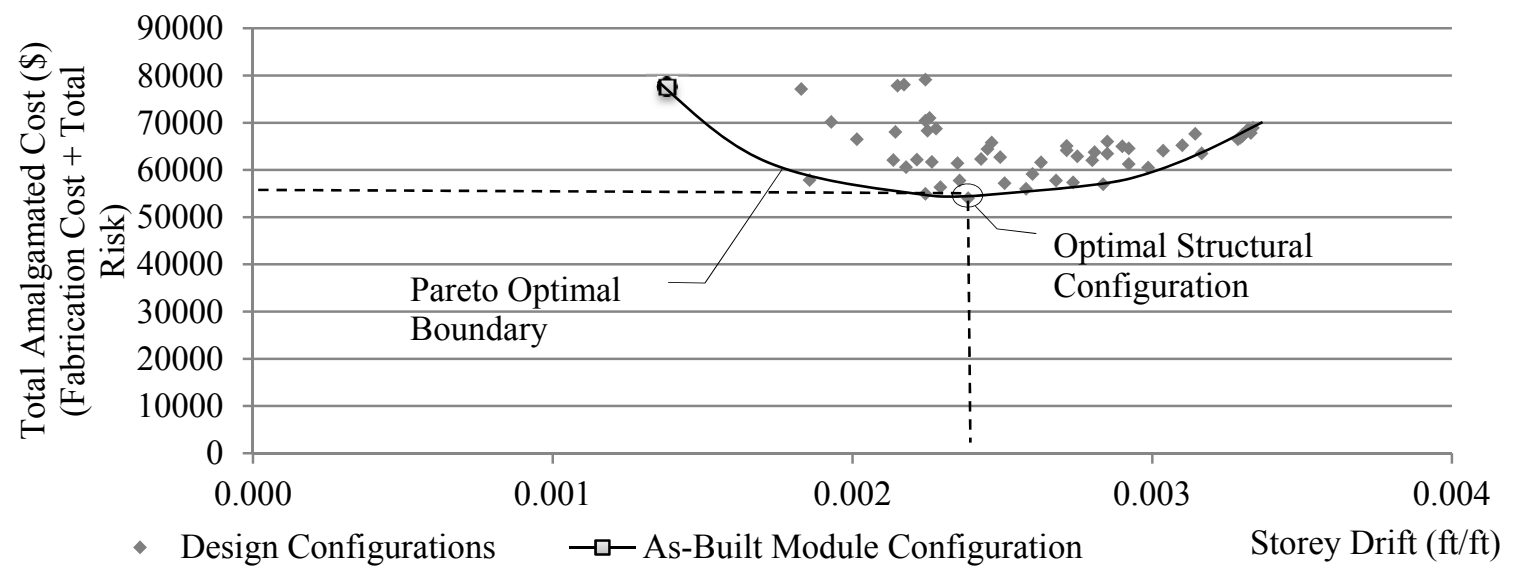

Figure 5. Amalgamated total cost function for all design configurations in tolerance strategy

After development of the tolerance strategy for this case study, some conclusions are evident. The as-built structural configuration has the strictest tolerance allowance (which means it is the 
stiffest module with the least distortion), however the data suggest that overall project costs could have been reduced by adopting a configuration with more flexibility. Comparison of the optimal and as-built configurations from a total cost standpoint (fabrication cost plus risk) reveals that fabrication cost can be reduced by $\$ 30,224$ by introducing a risk increase of only $\$ 6,624$ (Table 2 ). In this particular case study, the original module was overdesigned in order to avoid risk during modularization. This case study demonstrates that optimal risk mitigation can be achieved through the use of a tolerance strategy, allowing for the selection of a design which balances fabrication costs and risk.

Table 2. Comparison of as-built and optimal module configuration

\begin{tabular}{lll}
\hline Total Cost and Tolerance Criteria & As-Built Module & Optimal Module \\
\hline Fabrication Cost & $\$ 65,634$ & $\$ 35,410$ \\
$\begin{array}{l}\text { Total Risk (fabrication rework, transportation, } \\
\text { alignment, safety) }\end{array}$ & $\$ 12,009$ & $\$ 18,633$ \\
Amalgamated Total Cost & $\$ \mathbf{7 7 , 6 4 3}$ & $\mathbf{\$ 5 4 , 0 4 2}$ \\
Storey Drift (ft/ft) & $\mathbf{0 . 0 0 1 3 8}$ & $\mathbf{0 . 0 0 2 3 9}$ \\
\hline
\end{tabular}

\section{CONCLUSIONS AND FURTHER RESEARCH}

The proposed risk mitigation model has one main objective: to enable the modular designer to evaluate their design decisions from a total project perspective in order to balance fabrication cost and risk throughout modularization. This is carried out through the quantification of a fabrication cost function, a risk function and the development of tolerance metrics to compare design alternatives. While design decisions made in conventional "stick-built" construction scenarios are often based primarily on in-situ construction, more in-depth considerations are required in modularization due to risks emerging throughout fabrication, transportation, handling and erection of modules. Since the total cost for fabricating and assembling a modular project is not solely submerged into fabrication and material cost, design alternatives should be evaluated with respect to transportation, handling and erection measures. The insight shown in the proposed risk model through the use of tolerance strategies demonstrates that modular designers can make better informed decisions when evaluating design alternatives from a risk-based standpoint.

The case study in this paper focussed explicitly on the evaluation of module stiffness as the tolerance metric for the module assembly. Further validation of the proposed risk model can be achieved through the evaluation of additional tolerance metrics, such as the dimensional, positional or spatial orientation of modular components. Improvements to the proposed riskmitigation model include development of an algorithm to determine an appropriate level of detail and number of design iterations required for developing a tolerance strategy. Not every modular project will benefit from a detailed tolerance strategy, and therefore the level of detail for a tolerance strategy depends on degree of project complexity, degree of repetition, number of modules, and other factors. In addition, further research can focus on the use of tools to monitor and control tolerance strategies throughout fabrication, transportation and erection.

\section{ACKNOWLEDGEMENTS}

The writers would like to acknowledge the financial support of NSERC and PCL-Permanent Modular Construction, and SNC-Lavalin for contributing the detailed module information used in the case study. 


\section{REFERENCES}

Bosche, F., \& Haas, C. (2008). "Automated retrieval of 3D CAD model objects in construction range images." Automation in Construction, 499-512.

Burke, G. P., and Miller, R. (1998). "Modularization speeds construction." Power Engineering, 102(1), 20-22.

Chase, K. W., and Greenwood, W. H. (1988). "Design issues in mechanical tolerance analysis." Manufacturing Review, 1(1), 50-59.

Gadzala, J. L. (1959). "Dimensional control in precision manufacturing." Toronto: McGraw-Hill book company Inc.

Gann, D. M. (1996). "Construction as a manufacturing process? Similarities and differences between industrialized housing and car production in Japan." Construction Management \& Economics, 14(5), 437450 .

Gibb, A. G. (2001). "Standardization and pre-assembly-distinguishing myth from reality using case study research." Construction Management \& Economics, 19(3), 307-315.

Goodier, C. I., and Gibb, A. G. (2005). "Barriers and opportunities for offsite in the UK." Technical Research Center of Finland (VTT)/Association of Finnish Civil Engineers (RIL).

Haas, C. T., O'Connor, J. T., Tucker, R., Eickmann, J., and Fagerlund, W. R. (2000). "Prefabrication and preassembly trends and effects on the construction workforce." Center for Construction Industry Studies.

Hong, Y., and Chang, T. (2002). "A comprehensive review of tolerancing research." International Journal of Production Research, 40(11), 2425-2459.

Lu, N., and Korman, T. (2010). "Implementation of building information modeling (BIM) in modular construction: Benefits and challenges." Construction Institute of ASCE Reston, VA.

Milberg, C., and Tommelein, I. D. (2005). "Application of Tolerance Mapping in AEC Systems." Proceedings of Construction Research Congress. 2005.

Nadim, W., and Goulding, J. S. (2010). "Offsite production in the UK: the way forward? A UK construction industry perspective." Construction Innovation: Information, Process, Management, 10(2), 181-202.

Nahangi, M., Yeung, J., Haas, C., Walbridge, S., West, J. (2015). “Automated assembly discrepancy feedback using 3D imaging and forward kinematics", Automation in Construction, DOI: 10.1016/j.autcon.2015.04.005.

Neelamkavil, J. (2009). "Automation in the prefab and modular construction industry." 26th Symposium on Construction Robotics ISARC.

O' Connor, J., O' Brien, W., \& Choi, J. O. (2014). "Critical Success Factors and Enablers for Optimum and Maximum Indistrial Modularization ." Journal of Construction Engineering and Management.

Pan, W., Gibb, A. G. F., and Dainty, A. R. J. (2007). "Perspectives of UK housebuilders on the use of offsite modern methods of construction." Construction management and Economics, 25(2), 183-194.

Shahtaheri, Y. (2014). "A Risk Based Approach to Module Tolerance Specification." Master's Thesis, University of Waterloo, Canada.

Song, J., Fagerlund, W. R., Haas, C. T., Tatum, C. B., and Vanegas, J. A. (2005). "Considering prework on industrial projects." Journal of Construction Engineering and Management., 131(6), 723-733.

Sutherland, G., and Roth, B. (1975). "Mechanism design: accounting for manufacturing tolerances and costs in function generating problems." Journal of Manufacturing Science and Engineering, 97(1), 283286

Taylor, M., Fisher, A., and Wamuziri, S. C. (2009). "A comparison of modern methods of bathroom construction: A project case study." 25th Annual ARCOM Conference, Nottingham.

Waier, P. R., Babbitt, C., Baker, T., Balboni, B., \& Bastoni, R. A. (2009). "RSMeans Building Construction Cost Data." RS Means Company.

Yu, H., Al-Hussein, M., Al-Jibouri, S., \& Telyas, A. (2013). "Lean Transformation in a Modular Building Company." ASCE Journal of Management in Engineering, 103-111. 